\title{
Study on the Mechanical Effect and Constitutive Model of Montmorillonite under the Action of Acid Rain: A Case Study on Montmorillonite-Quartz Remolded Soil
}

\author{
$\mathrm{Li} \mathrm{Li}^{1,2}$ Jian Liu $\mathbb{D}^{3,4}$ and Xingqian $\mathrm{Xu}^{4,5}$ \\ ${ }^{1}$ School of Geosciences and Info-Physics, Central South University, Changsha 410012, China \\ ${ }^{2}$ Shanxi Earthquake Agency, Taiyuan 030000, China \\ ${ }^{3}$ School of Earth Science and Engineering, Hebei University of Engineering, Handan 056038, China \\ ${ }^{4}$ Institute of Mountain Hazards and Environment, Chinese Academy of Sciences, Chengdu 610041, China \\ ${ }^{5}$ College of Water Conservancy, Yunnan Agricultural University, Kunming 650000, China \\ Correspondence should be addressed to Jian Liu; liujian@hebeu.edu.cn
}

Received 11 October 2020; Revised 6 December 2020; Accepted 21 January 2021; Published 10 February 2021

Academic Editor: Chunshun Zhang

Copyright (C) $2021 \mathrm{Li} \mathrm{Li} \mathrm{et} \mathrm{al.} \mathrm{This} \mathrm{is} \mathrm{an} \mathrm{open} \mathrm{access} \mathrm{article} \mathrm{distributed} \mathrm{under} \mathrm{the} \mathrm{Creative} \mathrm{Commons} \mathrm{Attribution} \mathrm{License,} \mathrm{which}$ permits unrestricted use, distribution, and reproduction in any medium, provided the original work is properly cited.

\begin{abstract}
Clay minerals are the common insoluble cementing substances in soil. To study the mechanical effect of montmorillonite under the action of acid rain, the variation law and mechanism of the cohesive force and internal friction angle were discussed by immersing montmorillonite-quartz remolded soil in $\mathrm{HNO}_{3}$ solution with $\mathrm{pH}=3$. It was found that, under acidic conditions, the cohesive force increased after the first drop and subsequently decreased again, while the internal friction angle remained basically unchanged. Considering the vertical pressure of soil landslide, the change in the shear strength of cohesive soil under acid rain is consistent with the change in the cohesive force. The X-ray diffraction (XRD) results showed that the acid could erode the cementmontmorillonite, and no new substance was generated, which caused a decrease in cohesion. In addition, based on the microcementation nature of montmorillonite and the change mechanism of cohesion under acid rain, the cohesive force model of saturated montmorillonite-quartz remolded soil under acid rain was established. The change trend of calculated cohesion values was consistent with the one of measured values, and the error was small.
\end{abstract}

\section{Introduction}

Rainfall is the most common inducing factor of soil landslide, which is mainly reflected in the interaction between rainfall infiltration and soil, i.e., the water-soil interaction, among which the water-soil chemical action is important. Acid rain is a worldwide natural disaster with a strong corrosive effect. When acid rain infiltrates the soil, a strong water-soil chemical action will occur, which will change the composition and content of the soil and affect the physical and mechanical properties of the soil.

In response to the changes of soil physical and mechanical properties caused by acid rain, scholars have conducted relevant researches and made some progress. For example, Gu et al. [1] studied the shear strength of soil under the action of acid rain through the immersion experiment of remolded sandy silt and found that the cohesive force gradually decreased under the action of acid liquid and tended to be stable in the later period, while the internal friction angle slightly changed. The decrease in shear strength can induce landslide, and it was necessary to strengthen the research on the disaster mechanism of landslides caused by acid rain. Gratchev et al. [2] found that acid rain could erode $\mathrm{CaCO}_{3}$, the cement in soil, which resulted in a significant decrease in soil cohesion. Xiao et al. [3] found that compounds including iron, silicon, aluminum, and potassium in red clay could be eroded by acid rain and lost with the migration of groundwater, and this would increase the soil pore ratio. Bakhshipour et al. [4] studied the effect of acid rain on the physical and mechanical properties of residual soil and found that low-pH acid rain and high flux caused a decrease in soil strength and dry density, while 
the permeability coefficient, liquid limit, and optimal water content showed an increase. Gratchev et al. [5, 6] conducted compression tests on the natural soil, which was immersed in sulfuric acid solution, and found that the compression coefficient of the soil under a long-term acidic environment significantly increased, and the increase of the compression coefficient was negatively correlated with $\mathrm{pH}$. Zhang et al. [7] found that the shear strength of red clay in Yunnan showed a general downward trend under acid rain, and the reduction was positively correlated with the concentration of acid rain and contact time. The interactions between acid rain and red clay were summarized as follows: acid rain-red clay physical action, acid rain-red clay chemical action, and acid rain-red clay salt dissolution, replacement, crystallization, etc. Xia et al. [8] found that the strength of the river silt bubble mixed soil decreased after acid rain; the stronger the acid was, the more obvious the physical and mechanical properties changed. Li et al. [9] studied the disintegration mechanism of mudstone in acid rain area and found that the damage of mudstone mainly originated from the dissolution of specific minerals. With the decrease in $\mathrm{pH}$, the chemical damage of mudstone increased.

Current research mainly focused on the soils with poor mechanical properties (such as residual soil) and special soils (such as red clay and river silt bubble mixed soil), etc., and the damage mechanisms were studied from the perspective of the dissolution of calcium cement, iron cement, and soluble salt cement under acid rain. In addition, these soils are often distributed in specific areas, and the cementing materials are also regional and poor representative.

Clay minerals are the widely presented secondary minerals in natural soils and greatly affect the mechanical properties of soils. However, few researchers studied the mechanical effects of clay minerals under acid rain. In this study, the montmorillonite-quartz sand remolded soil was taken as the research object; by the immersion experiment, the mechanical effect and constitutive model of montmorillonite under the action of acid rain were studied. This work has important theoretical and practical significance for understanding the mechanism of soil landslide under acid rain and will take valued assistance for the prediction and prevention of landslide disaster.

\section{Materials and Methods}

2.1. Experimental Materials. The purity of the montmorillonite sample in this study is approximately $97 \%$, the average particle size is approximately $21.31 \mu \mathrm{m}$, the measured swelling degree is $7.50 \mathrm{ml} / \mathrm{g}$, and the specific surface area is $55.18 \mathrm{~m}^{2} / \mathrm{g}$. According to the XRD analysis, the chemical formula of the montmorillonite mineral in this study is $\mathrm{Ca}_{0.2}(\mathrm{Al}, \mathrm{Mg})_{2} \mathrm{Si}_{4} \mathrm{O}_{10}(\mathrm{OH})_{2} \cdot 4 \mathrm{H}_{2} \mathrm{O}$ (unit cell parameter: $a=0.5169 \mathrm{~nm}, \quad b=0.5169 \mathrm{~nm}, c=1.502 \mathrm{~nm}$, and density $(\mathrm{m})=2.30 \mathrm{~g} / \mathrm{cm}^{3}$ ) [10]. In addition, the montmorillonite sample also contains a small amount of quartz, tridymite, and muscovite.

As is well known, the main energy source in China is coal, so acid rain is mainly the sulfuric acid type. However, in recent years, with the rapid increasing number of cars, the demand for oil has increased year by year, and acid rain gradually changed to the nitric acid type with an increasing trend of acidity. The $\mathrm{pH}$ of acid rain in some areas is even less than 3 , and the minimum is approximately 2.8 [11]. In this study, the $\mathrm{HNO}_{3}$ solution with $\mathrm{pH}=3$ was used instead of acid rain to immerse montmorillonite and quartz sand remolded soil, and the mechanical effect of montmorillonite under acid rain was studied by the quick shear test.

\subsection{Research Methods}

2.2.1. Immersion Experiment. Previous studies [12] showed that the density of cohesive soil was $1.8 \sim 2.0 \mathrm{~g} / \mathrm{cm}^{3}$, and the density of sand soil was $1.6 \sim 2.0 \mathrm{~g} / \mathrm{cm}^{3}$, so the density of remolded soil in this study is set to $2.0 \mathrm{~g} / \mathrm{cm}^{3}$. In addition, the montmorillonite content in the sliding surface soil is much higher than that in the surrounding soil, and the content is approximately $10 \%[13,14]$. Therefore, the content of montmorillonite in this study was set at $10 \%$. The preparation process of remolded soil is as follows: firstly, we fully mixed the montmorillonite-quartz sand mixture, which was weighed according to the mixing ratio, added a certain amount of $\mathrm{pH}=3 \mathrm{HNO}_{3}$ solution, and thoroughly mixed again; after the controlled moisture content uniformly reached $17.65 \%, 120 \mathrm{~g}$ wet soil sample (including $91.8 \mathrm{~g}$ quartz sand, $10.2 \mathrm{~g}$ montmorillonite, and $18 \mathrm{~g} \mathrm{pH}=3 \mathrm{HNO}_{3}$ solution) was compacted in a $60 \mathrm{~cm}^{3}$ cutting ring $(\Phi 61.8 \times 20 \mathrm{~mm})$. Four prepared remolded soil samples were stacked together with the cutting ring in a $2 \mathrm{~L}$ large-diameter beaker. To prevent the soil samples from being dispersed, the soil samples were separated by permeable stones. Then, $1.8 \mathrm{~L} \mathrm{pH}=3 \mathrm{HNO}_{3}$ solution was injected into the beaker, which was immediately sealed with plastic wrap and placed in the incubator at constant temperature $\left(15^{\circ} \mathrm{C}, 20^{\circ} \mathrm{C}\right.$, and $\left.25^{\circ} \mathrm{C}\right)$ for the reaction. After the reaction reached the set time $(1 \mathrm{~d}, 5 \mathrm{~d}, 10 \mathrm{~d}$, and $15 \mathrm{~d})$, $\mathrm{pH}$ and electrical conductivity (EC) of the immersion solution were measured by using the multiparameter water quality detector (HQ30d), and then the quick shear tests were immediately performed to obtain the cohesion (c) and internal friction angle $(\varphi)$.

\subsubsection{Constitutive Model of Cementing Force between} Montmorillonite Layers. Researchers who comprehensively study the interaction between layers of montmorillonite minerals are Larid DA and Jia J. Larid [15] classified and studied the interaction between crystal layers from the energy perspective. Considering the deficiency of the Larid model, Jia [16] revised it from the force perspective and divided the forces between layers into two categories: attractive forces and repulsive forces. In this study, Jingchao Jia's model [16] was used to analyze the forces between montmorillonite layers.

The specific model and parameter values are as follows:

(1) Van der Waals force [16]: 


$$
F_{v}=\frac{H}{6 \pi}\left[\frac{1}{\lambda^{3}}+\frac{1}{(\lambda+2 x)^{3}}-\frac{2}{(\lambda+x)^{3}}\right] \text {, }
$$

where $F_{v}$ is the Van der Waals force, $H$ is the Hamaker constant with the value of $2.2 \times 10^{-20} \mathrm{~J}, x$ is the thickness of the crystal layer, and $\lambda$ is the distance between crystal layers.

(2) Electrostatic attraction of cations between layers [16]:

$$
F_{a i}=\frac{\omega^{2}}{\varepsilon_{0} \varepsilon_{r}} \times 2,
$$

where $F_{a i}$ is the electrostatic attraction of cations between layers to the crystal layers on both sides; $\omega$ is the surface charge density of the crystal layer $\left(\mathrm{C} / \mathrm{m}^{2}\right)$; $\varepsilon_{0}$ is the vacuum permittivity, which takes a value of $8.854 \times 10^{-12} \mathrm{C}^{2} / \mathrm{Nm}^{2}$; and $\varepsilon_{r}$ is the relative permittivity between layers, which is a function of the distance between crystal layers:

$$
\varepsilon_{r}=\left[1+\tanh \left(\frac{\lambda-C_{1}}{C_{2}}\right)\right]\left(\frac{\varepsilon_{b}-\varepsilon_{c}}{2}\right)+\varepsilon_{c},
$$

where $\varepsilon_{b}$ is the relative permittivity of the bulk phase with a value of 78.15 ; $\varepsilon_{c}$ is the relative permittivity of the crystal layer with a value of 6 ; and $C_{1}$ and $C_{2}$ are the empirical parameters with values of $1.46 \times 10^{-9} \mathrm{~m}$ and $9.0 \times 10^{-10} \mathrm{~m}$, respectively.

$$
\begin{aligned}
\omega & =\varepsilon_{r} \varepsilon_{0} \frac{2 k T K}{e v} \tan \frac{K \lambda}{2}, \\
K & =\sqrt{\frac{(e v)^{2} n N_{A}}{2 \varepsilon_{r} \varepsilon_{0} k T}},
\end{aligned}
$$

where $e$ is the unit charge quantity, which takes the value of $1.602 \times 10^{-19} \mathrm{C}$; $v$ is the ion valence; the ion between the montmorillonite layer groups in this study is calcium ion, so $v$ is taken as $2 ; n$ is the cation concentration between crystal layers; $N_{A}$ is the Avogadro constant with the value of $6.02 \times 10^{23} \mathrm{~mol}^{-1} ; T$ is the absolute temperature; and $k$ is Boltzmann constant with the value of $1.38 \times 10^{-23} \mathrm{~J} / \mathrm{K}$.

(3) Cation hydration force [16]:

$$
F_{\mathrm{hi}}=\frac{e v \omega}{4 \pi \varepsilon_{0}\left(r_{i}+\delta_{s}\right)} \frac{1}{\varepsilon_{r}^{2}} \frac{\varepsilon_{b}-\varepsilon_{c}}{2 C_{2}\left[\cosh \left(\left(\lambda-C_{1}\right) / C_{2}\right)\right]^{2}},
$$

where $F_{\text {hi }}$ is the cation hydration force; $r_{i}$ is the effective radius of cation, and it is taken as $0.1 \mathrm{~nm}$ for calcium ion; and $\delta_{s}$ is always related to the radius of the cation and usually taken as $0.054 \mathrm{~nm}$.
(4) Hydration force of the crystal layer surface [16]:

$$
F_{\mathrm{hs}}=\frac{e \omega}{8 \pi \varepsilon_{0}\left(r_{s}+\delta_{s}\right)} \frac{1}{\varepsilon_{r}^{2}} \frac{\varepsilon_{b}-\varepsilon_{c}}{2 C_{2}\left[\cosh \left(\left(\lambda-C_{1}\right) / C_{2}\right)\right]^{2}},
$$

where $F_{\mathrm{hs}}$ is the hydration force of the crystal layer surface and $r_{s}$ is half of the thickness of the crystal layer.

(5) Electrostatic repulsion force between layer groups [16]:

$$
F_{\mathrm{rs}}=\frac{\omega^{2}}{2 \varepsilon_{0} \varepsilon_{r}}
$$

where $F_{\mathrm{rs}}$ is the electrostatic repulsion force between layer groups.

(6) Born Repulsion Force [16]:

$$
F_{b}=\frac{12 L}{\lambda^{13}}
$$

where $F_{\mathrm{b}}$ is the Born repulsion force and $L$ is a constant with a value of $1.4627 \times 10^{-124} \mathrm{Jm}^{10}$.

(7) Osmotic pressure [16]:

$$
F_{o}=k T N_{A}\left(n-n_{0}\right),
$$

where $F_{\mathrm{o}}$ is the osmotic pressure and $n$ and $n_{0}$ are the cation concentration inside and outside the crystal layer, respectively.

Thus, cementing force $F$ between the montmorillonite layers is the combined force of the above seven types of forces:

$$
F=F_{v}+F_{\mathrm{ai}}-F_{\mathrm{hi}}-F_{\mathrm{hs}}-F_{\mathrm{rs}}-F_{b}-F_{o} .
$$

\subsubsection{Constitutive Cohesion Model of Saturated Montmo-} rillonite-Quartz Sand Remolded Soil. In this study, montmorillonite is the only one cement in the remolded soil. The key to obtaining the theoretical value of cohesive force is to find the total cementation strength generated by the cementing forces between the montmorillonite layers on the shear plane.

The unit of cementing force between montmorillonite layers is $\mathrm{N} / \mathrm{m}^{2}$. In order to calculate cohesion, the interaction area of montmorillonite (effective contact area of montmorillonite) $S_{E}$ on the shear plane must be obtained. Then the cohesive force of saturated montmorillonite-quartz sand remolded soil can be calculated as follows:

$$
c=\frac{F \times S_{E}}{S},
$$


where $c$ is the cohesive force, $S_{E}$ is the effective contact area of montmorillonite on the shear plane, and $S$ is the shear area.

(1) Method to obtain the spacing between montmorillonite layers: the above models of all seven-component force calculation formulas of cementing force $F$ showed that the spacing $\lambda$ between montmorillonite layers was the key to obtain $F$. In this study, the saturated soil sample contains high swelling montmorillonite, and $\lambda$ is affected by the volume of montmorillonite bound water. If the swelling volume of montmorillonite is greater than or equal to the pore volume of soil, the following relationship can be obtained $[17,18]$ :

$$
\begin{gathered}
V_{w}=V_{v}=M \cdot S_{s} \cdot d, \\
d=\frac{\lambda}{2}=\frac{V_{w}}{M S_{s}}=\frac{V_{v}}{M S_{s}},
\end{gathered}
$$

where $V_{w}$ is the volume of water in the remolded soil, $V_{v}$ is the pore volume of soil, $M$ is the mass of montmorillonite sample in soil, $S_{s}$ is the specific surface area of montmorillonite sample, and $d$ is half of the spacing between montmorillonite layers.

To verify whether montmorillonite fills the soil pores, the concept of net swelling degree $Z$ is introduced in this study, which is the volume increment of montmorillonite per unit mass after free expansion in water:

$$
Z=\frac{V_{\mathrm{mw}}-V_{m}}{M_{m}},
$$

where $Z$ is the net swelling degree, $M_{m}$ is the mass of montmorillonite, $V_{\mathrm{mw}}$ is the total volume of montmorillonite after saturated, and $V_{m}$ is the volume of montmorillonite in the dry state.

The pore volume $V_{\mathrm{v}}$ in the soil can be obtained as follows:

$$
V_{v}=V-\frac{W_{s}}{G_{s} \gamma_{w}},
$$

where $W_{s}$ is the mass of soil particles and $\gamma_{w}$ is the bulk density of water.

If $Z \cdot M_{m} \geq V_{v}$, the montmorillonite completely fills the pores of soil sample and satisfies the requirements of the model. If $Z \cdot M_{m}<V_{v}$, the following relationship works:

$$
\begin{aligned}
Z \cdot M_{m} & =M \cdot S_{s} \cdot d, \\
d & =\frac{\lambda}{2}=\frac{Z \cdot M_{m}}{M S_{s}} .
\end{aligned}
$$

In this study, specific gravity $G_{s}$ is tested as 2.65 , so pore volume $V_{\mathrm{v}}$ in the remolded soil can be calculated as $21.45 \mathrm{ml}$. The swelling degree of the montmorillonite sample is approximately $7.50 \mathrm{ml} / \mathrm{g}$, net swelling degree $Z$ is $7.30 \mathrm{ml} / \mathrm{g}$, and the volume increment of the montmorillonite sample with a purity of $97 \%$ of $10.2 \mathrm{~g}$ is $72.23 \mathrm{ml}$, which is much larger than the pore volume of $21.45 \mathrm{ml}$. Thus, montmorillonite in the remolded soil swells and fills the pores of the soil, and the water in the soil is all located between montmorillonite crystal layers, which satisfies the requirements of the model.

(2) Method to obtain the effective contact area of montmorillonite on the shear plane: in this study, the interaction area of montmorillonite on the shear plane is defined as the effective contact area, and it can be obtained as follows:

(1) Calculation of the montmorillonite area on shear plane: assuming that montmorillonite is evenly distributed in the entire remolded soil, the following relation can be obtained:

$$
S_{m}=\frac{V_{m}}{h}=\frac{M_{m}}{\rho h},
$$

where $S_{m}$ is the montmorillonite area on the shear plane, $h$ is the height of the remolded soil sample, and $\rho$ is the density of montmorillonite.

(2) Calculation of the effective contact area: the contact probability with montmorillonite on the shear plane is the ratio of the montmorillonite area $S_{m}$ on the shear plane to the shear plane area $S$. Then, the effective montmorillonite contact area $S_{E}$ on the shear plane can be expressed as follows:

$$
S_{E}=S_{m} \times \frac{S_{m}}{S}
$$

(3) Cohesion model of saturated montmorillonitequartz sand remolded soil:

$$
c=\frac{F \times S_{E}}{S}=F \times \frac{S_{m}^{2}}{S^{2}} .
$$

2.2.4. Method to Establish the Chemical Reaction Rate Equation. Previous studies [3, 6, 7] showed that acid rain could react with cementing substances in soil, which affected the mechanical effect of soil particles. In this study, only one cement-montmorillonite is in the remolded soil, while quartz sand has strong acid resistance, so only montmorillonite will react with the $\mathrm{HNO}_{3}$ solution.

During the experimental process of this study, the contents of montmorillonite and $\mathrm{HNO}_{3}$ were constantly changing, and these changes followed the chemical reaction kinetics. Only by establishing the corresponding chemical reaction rate equation, we can provide parameters for the 
cohesive force model and realize the simulation calculation of the cohesive force.
The chemical reaction in this process is as follows:

$$
\mathrm{Ca}_{0.2}(\mathrm{Al}, \mathrm{Mg})_{2} \mathrm{Si}_{4} \mathrm{O}_{10}(\mathrm{OH})_{2} \times 4 \mathrm{H}_{2} \mathrm{O}+\mathrm{HNO}_{3}{ }^{\circledR} \mathrm{Ca}\left(\mathrm{NO}_{32}\right)+\mathrm{Mg}\left(\mathrm{NO}_{32}\right)+\mathrm{Al}\left(\mathrm{NO}_{33}\right)+\mathrm{SiO}_{2}{ }^{-}+\mathrm{H}_{2} \mathrm{O}
$$

In this study, the following method [19] was used to establish the reaction rate equation:

$$
\gamma=\frac{d\left[\mathrm{Al}^{3+}\right]}{d t}=k\left[M_{t}\right]^{\alpha}\left[\mathrm{HNO}_{3}\right]^{\beta},
$$

where $\gamma$ is the reaction rate of montmorillonite and $\mathrm{HNO}_{3}$ at $\mathrm{T}^{\circ} \mathrm{C} ;\left[A l^{3+}\right],\left[\mathrm{M}_{t}\right]$, and $\left[\mathrm{HNO}_{3}\right]$ are the concentrations of $\mathrm{Al}^{3+}$, montmorillonite, and $\mathrm{HNO}_{3}$ in the reaction system, respectively; $t$ is the reaction time; $\alpha$ and $\beta$ are the reaction order of montmorillonite and nitric acid; and $k$ is the rate constant.

Obviously, $\gamma=d\left[\mathrm{Al}^{3+}\right] / d t$ can be measured from the experiment, $k, \alpha$, and $\beta$ are the three desired parameters, and there must be three equations to solve. Thus, these parameters can be obtained by arranging a set of three tests, but the three tests must have a certain concentration relationship [19] (Table 1).

By substituting the data in Table 1 into (20), one ternary equation set can be obtained:

$$
\left\{\begin{array}{l}
\gamma_{1}=\frac{d\left[\mathrm{Al}^{3+}\right]_{1}}{d t_{1}}=k\left[\mathrm{M}_{t}\right]_{1}^{\alpha}\left[\mathrm{HNO}_{3}\right]_{1}^{\beta}, \\
\gamma_{2}=\frac{d\left[\mathrm{Al}^{3+}\right]_{2}}{d t_{2}}=k\left[\mathrm{M}_{t}\right]_{1}^{\alpha}\left[\mathrm{HNO}_{3}\right]_{2}^{\beta}, \\
\gamma_{3}=\frac{d\left[\mathrm{Al}^{3+}\right]_{3}}{d t_{3}}=k\left[\mathrm{M}_{t}\right]_{3}^{\alpha}\left[\mathrm{HNO}_{3}\right]_{1}^{\beta} .
\end{array}\right.
$$

The results are as follows:

$$
\begin{aligned}
& \alpha=\frac{\lg \gamma_{1}-\lg \gamma_{3}}{\lg \left[M_{t}\right]_{1}-\lg \left[M_{t}\right]_{3}}, \\
& \beta=\frac{\lg \gamma_{1}-\lg \gamma_{2}}{\lg \left[H N O_{3}\right]_{1}-\lg \left[H N O_{3}\right]_{2}}, \\
& k=\frac{\gamma_{1}}{\left[M_{t}\right]_{1}^{\alpha}\left[\mathrm{HNO}_{3}\right]_{1}^{\beta}}=\frac{\gamma_{2}}{\left[M_{t}\right]_{2}^{\alpha}\left[\mathrm{HNO}_{3}\right]_{2}^{\beta}}=\frac{\gamma_{3}}{\left[M_{t}\right]_{3}^{\alpha}\left[\mathrm{HNO}_{3}\right]_{3}^{\beta}} .
\end{aligned}
$$

By substituting the solved $k, \alpha$, and $\beta$ into (20), the reaction rate equation at $\mathrm{T}^{\circ} \mathrm{C}$ can be obtained.

The montmorillonite chemical formula $\mathrm{Ca}_{0.2}(\mathrm{Al}, \mathrm{Mg})_{2}$ $\mathrm{Si}_{4} \mathrm{O}_{10}(\mathrm{OH})_{2} \cdot 4 \mathrm{H}_{2} \mathrm{O}$ in this study is the chemical formula after the isomorphous replacement and cation exchange. Its initial chemical formula is $\mathrm{Al}_{2} \mathrm{Si}_{4} \mathrm{O}_{10}(\mathrm{OH})_{2} \cdot 4 \mathrm{H}_{2} \mathrm{O}$, and the chemical reaction equation is as follows:

$$
\mathrm{Al}_{2} \mathrm{Si}_{4} \mathrm{O}_{10}(\mathrm{OH})_{2} \times 4 \mathrm{H}_{2} \mathrm{O}+6 \mathrm{HNO}_{3}=2 \mathrm{Al}\left(\mathrm{NO}_{33}\right)+4 \mathrm{SiO}_{2}{ }^{-}+8 \mathrm{H}_{2} \mathrm{O}
$$

In addition, the chemical reaction rate in (20) is the formation rate of $\mathrm{Al}^{3+}$, and the consumption rate of montmorillonite under acid rain can be calculated based on the chemical reaction formula by using the generated amount of $\mathrm{Al}^{3+}$. The principle is as follows [20].

For any chemical reaction,

$$
a A+b B \longrightarrow g G+h H .
$$

The chemical reaction rate $J$ can be written as

$$
J=-\frac{1}{a} \frac{d n_{A}}{d t}=-\frac{1}{b} \frac{d n_{B}}{d t}=\frac{1}{g} \frac{d n_{G}}{d t}=\frac{1}{h} \frac{d n_{H}}{d t} .
$$

For a sealed reaction vessel with a certain volume, it can be characterized by unit volume reaction rate $r$ :

$$
r=-\frac{1}{a} \frac{d[A]}{d t}=-\frac{1}{b} \frac{d[B]}{d t}=\frac{1}{g} \frac{d[G]}{d t}=\frac{1}{h} \frac{d[H]}{d t} .
$$

\section{Results}

\subsection{Mechanical Effect of Montmorillonite under Acid Rain}

3.1.1. Variation of the Immersion Liquid Parameters and Cohesive Force. Under certain temperature conditions $\left(15^{\circ} \mathrm{C}, 20^{\circ} \mathrm{C}\right.$, and $\left.25^{\circ} \mathrm{C}\right)$, by immersing montmorillonitequartz sand remolded clay in the $\mathrm{pH}=3 \mathrm{HNO}_{3}$ solution for a certain time $(1 \mathrm{~d}, 5 \mathrm{~d}, 10 \mathrm{~d}$, and $15 \mathrm{~d})$, and combining the changes of the immersion liquid parameters and cohesive force, the influence of acid rain on the cohesive force was studied. The results are shown in Figure 1.

At all temperatures, the $\mathrm{pH}$ of the soaking solution increased, and the electrical conductivity decreased, which indicated that montmorillonite reacted with the strong acid $\mathrm{HNO}_{3}$, consumed $\mathrm{H}^{+}$, and produced the corresponding nitrate. Under the same concentration conditions, because the electrical conductivity of soluble salt was usually weaker than that of the corresponding strong acid, the electrical conductivity of the immersion liquid generally showed a decline. After 1 day, the $\mathrm{pH}$ at $15^{\circ} \mathrm{C}, 20^{\circ} \mathrm{C}$, and $25^{\circ} \mathrm{C}$ was 3.45 , 3.51 , and 3.78 , respectively; after 15 days, the $\mathrm{pH}$ at $15^{\circ} \mathrm{C}$, $20^{\circ} \mathrm{C}$, and $25^{\circ} \mathrm{C}$ was $4.84,5.51$, and 6.57 , respectively; this indicated that, after the same immersion time, the $\mathrm{pH}$ increased with the increase of temperature. The decrease of electrical conductivity also showed the same trend. Hence, temperature has a great promoting effect on the chemical reaction between $\mathrm{HNO}_{3}$ and montmorillonite. In addition, the cohesive force showed the characteristic of first decreasing, subsequently increasing, and then decreasing again 
TABLE 1: Concentration relationship between montmorillonite and $\mathrm{HNO}_{3}$.

\begin{tabular}{lcccc}
\hline Test order & $\begin{array}{c}\text { Montmorillonite concentration (mol/ } \\
\mathrm{L})\end{array}$ & $\begin{array}{c}\text { Nitric acid concentration } \\
(\mathrm{mol} / \mathrm{L})\end{array}$ & Reaction time (h) & Aluminum ion concentration (mol/L) \\
\hline 1 & {$\left[\mathrm{M}_{t}\right]_{1}$} & {$\left[\mathrm{HNO}_{3}\right]_{1}$} & $t_{1}$ & {$\left[\mathrm{Al}^{3+}\right]_{1}$} \\
2 & {$\left[\mathrm{M}_{t}\right]_{2}=\left[\mathrm{M}_{t}\right]_{1}$} & {$\left[\mathrm{HNO}_{3}\right]_{2}$} & $t_{2}$ & {$\left[\mathrm{Al}^{3+}\right]_{2}$} \\
3 & {$\left[\mathrm{M}_{t}\right]_{3}$} & {$\left[\mathrm{HNO}_{3}\right]_{3}=\left[\mathrm{HNO}_{3}\right]_{1}$} & $t_{3}$ & {$\left[\mathrm{Al}^{3+}\right]_{3}$} \\
\hline
\end{tabular}

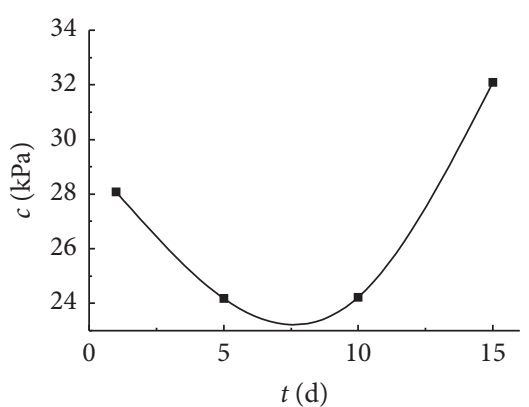

15 degrees centigrade

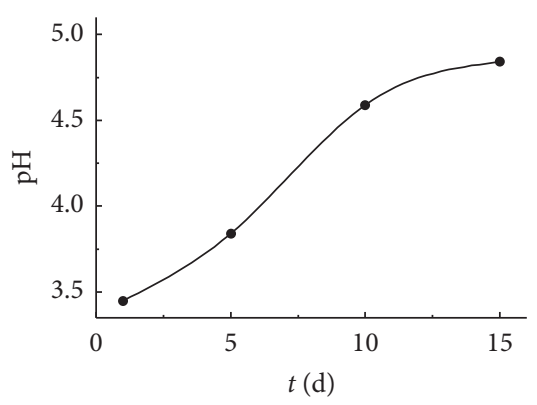

15 degrees centigrade

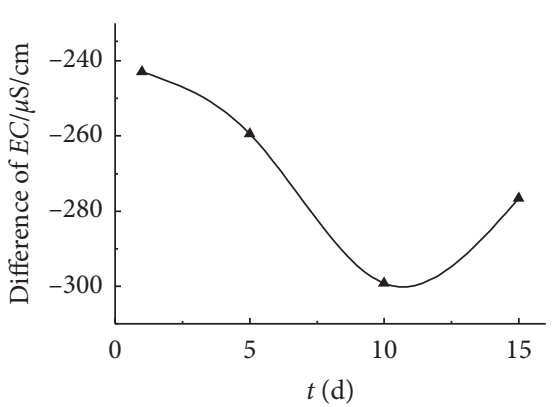

15 degrees centigrade

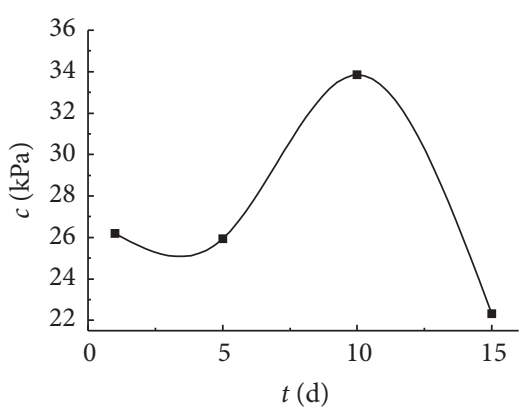

20 degrees centigrade

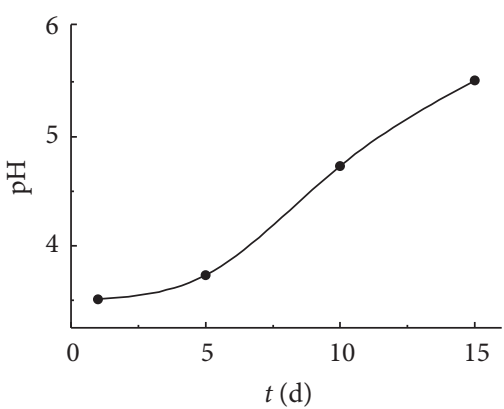

20 degrees centigrade

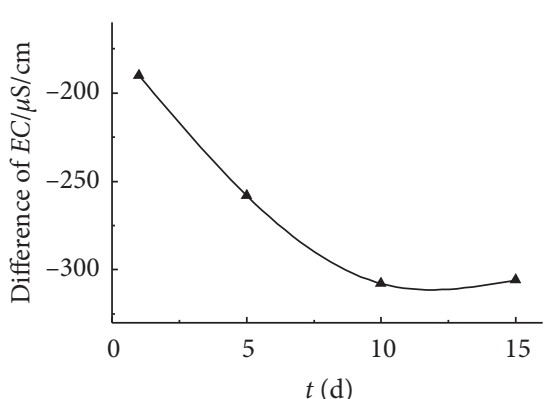

20 degrees centigrade

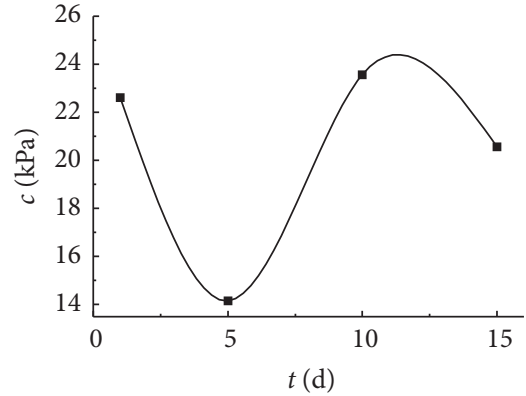

25 degrees centigrade

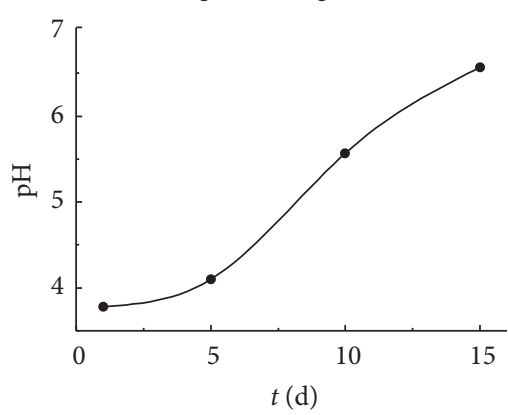

25 degrees centigrade

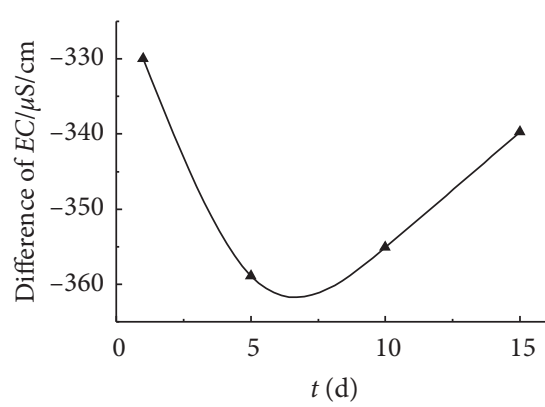

25 degrees centigrade

Figure 1: Variable characteristics of the soaking liquid parameters and cohesive force $\left(\mathrm{HNO}_{3}\right)$.

in general. At $15^{\circ} \mathrm{C}$, the cohesive force of soil first decreased and subsequently increased, while at $20^{\circ} \mathrm{C}$ and $25^{\circ} \mathrm{C}$, the cohesive force first decreased, subsequently increased, and then decreased. At the higher temperature, the change stage of cohesion was more complete, which also reflects the promoting effect of temperature.

To further clarify the acid rain effect on the cohesive force, the time points at $20^{\circ} \mathrm{C}$ were added, and the results are shown in Figure 2. With the extension of time, $\mathrm{pH}$ gradually increased, and the electrical conductivity decreased. The cohesive force generally first decreased, subsequently increased, and subsequently decreased. These changes were completely consistent with the previously summarized laws.

\subsubsection{Changes of Internal Friction Angle and Shear Strength} under Acid Rain. To clarify the acid rain effect, this study also analyzed the internal friction angle and the shear strength by combining with the cohesion and vertical pressure of soil landslide.

Figure 3 shows that, under acidic conditions, when the cohesive force changed, the internal friction angle remained 

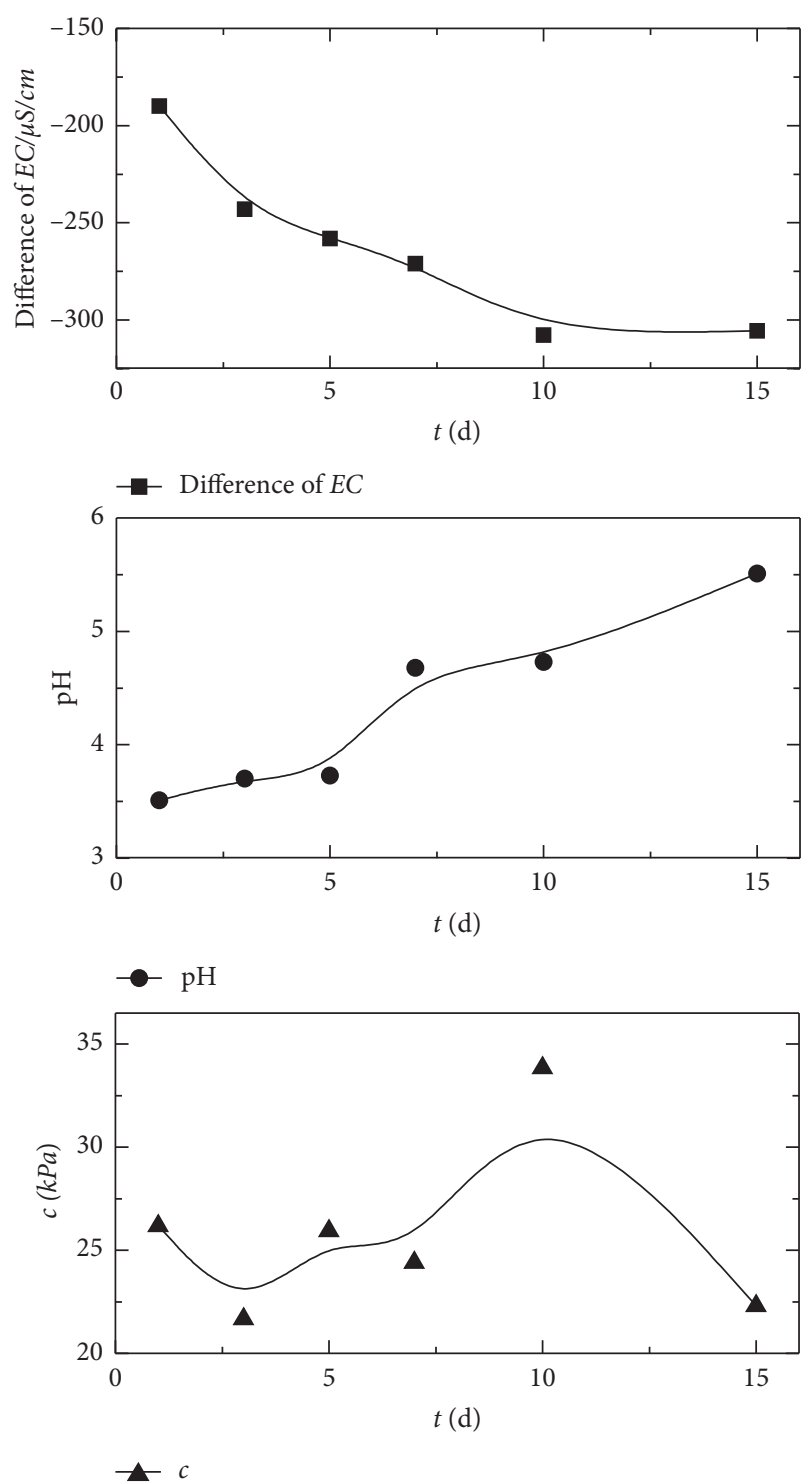

FIGURE 2: Characteristic verification of the soaking liquid parameters and cohesive force $\left(20^{\circ} \mathrm{C}, \mathrm{HNO}_{3}\right)$.

basically unchanged, and the overall variation was smaller than that of the cohesive force. Based on the above changes in cohesion and internal friction angle, combined with the lower vertical pressure provided by the soil landslide body (the thickness of the soil landslide body was mainly 0-5 m and 5-10 $\mathrm{m} \mathrm{[21]} \mathrm{and} \mathrm{the} \mathrm{vertical} \mathrm{pressure} \mathrm{was} \mathrm{only} \mathrm{ap-}$ proximately $0.1-0.2 \mathrm{MPa}$ ), according to Coulomb's law [22], it was not difficult to infer that the change in soil shear strength under acid rain was consistent with the change in cohesive force.

\subsubsection{Mechanism of Montmorillonite Mechanical Effect} under Acid Rain. To clarify the mechanism of montmorillonite mechanical effect under acid rain, X-ray diffraction analysis was performed on the montmorillonite samples before and after immersing in $\mathrm{pH}=3 \mathrm{HNO}_{3}$, and the XRD spectrums were overlaid as shown in Figure 4.

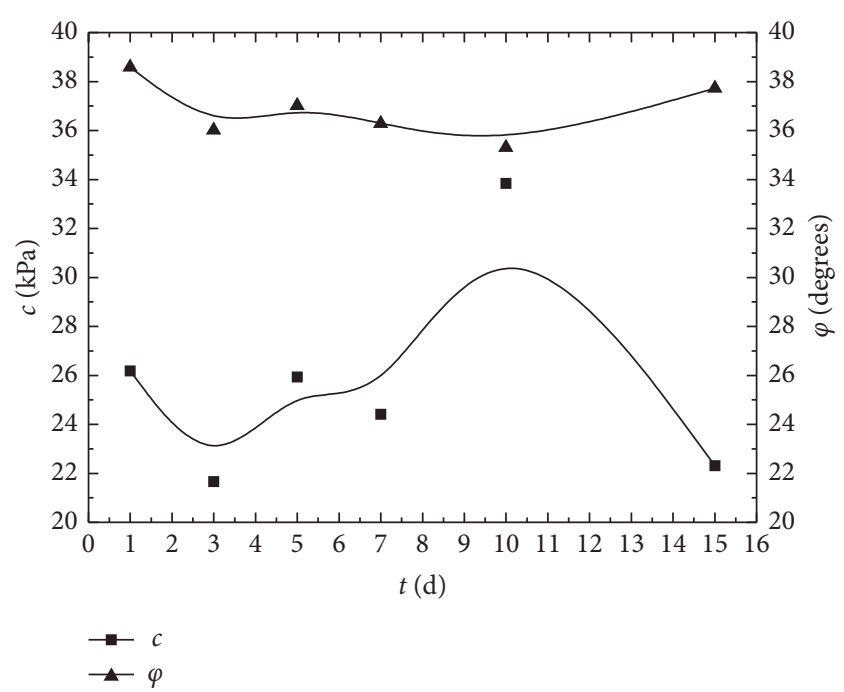

FIGURE 3: Variable characteristics of the cohesive force and internal friction angle under acid condition.

After montmorillonite being immersed in the acid solution, the characteristic peak intensity of the montmorillonite mineral at the diffraction angle of $5.71^{\circ}$ showed a large drop from 1990 to 1204, and the diffraction angle before and after soaking changed from $5.71^{\circ}$ to $5.79^{\circ}$. In addition, the characteristic peak intensity of montmorillonite at approximately $29^{\circ} \mathrm{de}$ creased from 495 to 201, and the diffraction angle before and after immersion also changed from $29.47^{\circ}$ to $29.06^{\circ}$. The intensity and the characteristic diffraction angle of other components in the montmorillonite sample did not significantly change, and no new characteristic peaks appeared. This indicated that, after the interaction with $\mathrm{HNO}_{3}$, the montmorillonite had a large loss, and no new solid material was generated.

Considering the changes in $\mathrm{pH}$ and conductivity, it could be believed that $\mathrm{HNO}_{3}$ would greatly erode montmorillonite and cause the decrease of cohesive force. The increase of cohesive force in the middle of immersion indicates that there must be a substance that provides greater cohesion, but the XRD results show that no new substance was generated. In this study, the phenomenon of increased cohesion in the middle stage of acid immersion appeared more than once. The reason was not clear and required further study.

In terms of internal friction angle, previous studies [23-26] showed that the main factors that affected the internal friction angle were the density, particle size, particle shape, mineral composition, etc. The X-ray diffraction analysis result showed that, under acidic conditions, only montmorillonite was eroded in the remolded soil, quartz sand had no loss, and no new substance was generated. Since the remolded soil in this study was mainly composed of quartz sand, the content of montmorillonite was low, and the acid solution had limited effect on the above factors, so the internal friction angle basically remained unchanged. 


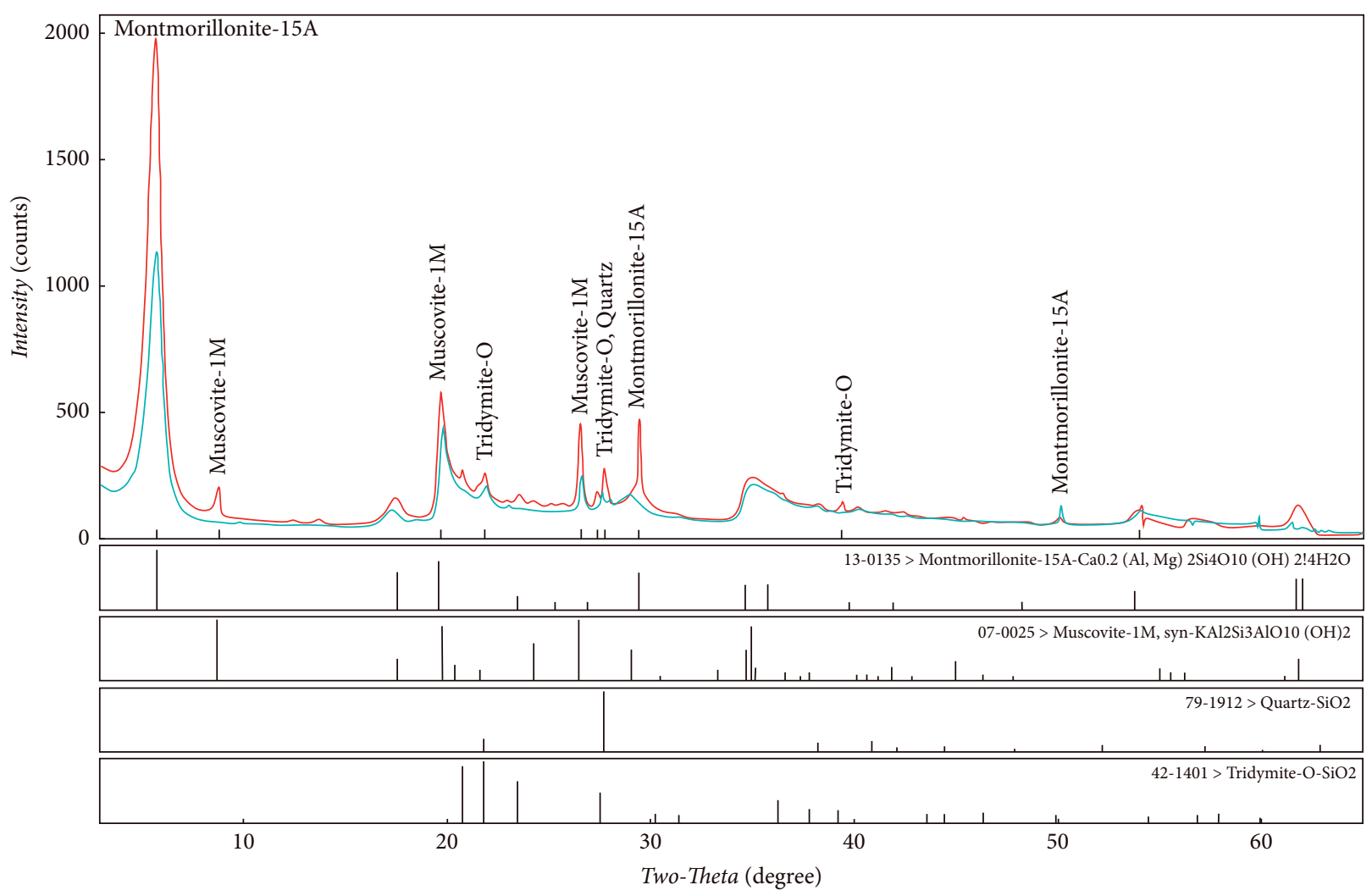

Montmorillonite sample $+\mathrm{HNO}_{3}$

Montmorillonite sample

FIGURE 4: XRD spectrums of montmorillonite before and after soaking in $\mathrm{HNO}_{3}$ solution.

\subsection{Constitutive Model of Montmorillonite Mechanical Effect under Acid Rain}

\subsubsection{Constitutive Model of the Cohesive Force of Saturated} Remolded Soil under Acid Rain. The previous study showed that, under the action of acid rain, the cohesion of the montmorillonite-quartz sand remolded soil greatly changed, while the internal friction angle was little changed. Therefore, this study mainly focused on the cohesion model of saturated montmorillonite-quartz sand remolded soil under acid rain.

According to the foregoing analysis, acid rain can erode montmorillonite, which leads to changes of cohesive force. By establishing the chemical reaction rate equation of montmorillonite- $\mathrm{HNO}_{3}$, the mass change of montmorillonite at any time can be obtained.

In addition, to make the model closer to reality, it is necessary to revise the cohesive force model of saturated montmorillonite-quartz sand remolded soil. The revisions are mainly reflected in two aspects:

(1) Assuming that the soil particles in the saturated remolded soil were distributed evenly, when the montmorillonite particles are eroded by $\mathrm{HNO}_{3}$, the remaining montmorillonite cannot continue to expand crossing the quartz sand due to the quartz sand barrier. The dissolution volume existed in the form of pores, which is consistent with the scanning electron microscopy results [27]. Therefore, the spacing between montmorillonite layers would not increase during the reaction.

(2) The effective contact area is the area where montmorillonite layers contact each other on the shear plane. Once the remolded soil is prepared, the contact relationship between soil particles is determined. If the montmorillonite on either side is eroded by acid, the other side loses contact object, so the effective contact area will be reduced. For the two sides of the shear plane, the actual reduced effective contact area is twice that of one side.

Based on the above considerations, the cohesive force of saturated montmorillonite-quartz sand remolded soil under acid rain can be expressed as

$$
\begin{aligned}
& S_{E}^{\prime}=S_{E}-2\left(\frac{\gamma \cdot t}{\rho \cdot h} \cdot \frac{S_{E}}{S_{m}}\right), \\
& c^{\prime}=\frac{F \times S_{E}^{\prime}}{S},
\end{aligned}
$$

where $c^{\prime}$ is the cohesive force of saturated montmorillonitequartz sand remolded soil under acid rain, $S_{E}^{\prime}$ is the effective montmorillonite contact area on the shear plane after reaction time $t$, and $\gamma$ is the reaction rate of montmorillonite at $\mathrm{T}^{\circ} \mathrm{C}$. 
TABLe 2: Experimental data of the chemical reaction kinetics.

\begin{tabular}{lccccccc}
\hline $\begin{array}{l}\text { Temperature } \\
\left({ }^{\circ} \mathrm{C}\right)\end{array}$ & $\begin{array}{c}\text { Test } \\
\text { order }\end{array}$ & $\begin{array}{c}\text { Sample } \\
\text { mass }(\mathrm{g})\end{array}$ & $\begin{array}{c}\text { Montmorillonite } \\
\text { concentration }(\mathrm{mol} / \mathrm{L})\end{array}$ & $\begin{array}{c}\mathrm{HNO}_{3} \\
\text { concentration } \\
(\mathrm{mol} / \mathrm{L})\end{array}$ & $\begin{array}{c}\mathrm{HNO}_{3} \text { volume } \\
(\mathrm{ml})\end{array}$ & $\begin{array}{c}\text { Reaction time } \\
(\mathrm{h})\end{array}$ & $\begin{array}{c}\mathrm{Al}^{3+} \text { formation rate } \\
(\mathrm{mol} / \mathrm{L} / \mathrm{h})\end{array}$ \\
\hline & 1 & 0.96 & 0.0035 & 0.001 & 600 & 122.69 & $2.27 \mathrm{E}-08$ \\
20 & 2 & 0.96 & 0.0035 & 0.01 & 600 & 25.07 & $4.47 \mathrm{E}-07$ \\
& 3 & 1.92 & 0.0070 & 0.001 & 600 & 71.88 & $4.07 \mathrm{E}-08$ \\
\hline
\end{tabular}

Since the mechanism of the increase of cohesive force in the middle stage was not clear and the total change trend of the cohesive force was reduction, the increased cohesion was not considered in this model.

3.2.2. Reaction Rate Equation. According to the abovementioned method, a certain amount of montmorillonite was immersed in $600 \mathrm{ml}$ of $\mathrm{HNO}_{3}$ solution with different concentrations, and the temperature was constant at $20^{\circ} \mathrm{C}$. Once the reaction reached the set time, the $\mathrm{Al}^{3+}$ concentration in the immersion solution was immediately measured by using an ultraviolet-visible spectrophotometer (Shimazu Co., UV-2600). The specific experimental data are shown in Table 2, and the calculation results of the reaction order and rate constant are shown in Table 3.

Then, the chemical reaction rate of montmorillonite and $\mathrm{HNO}_{3}$ can be expressed as follows:

$$
20^{\circ} \mathrm{C}, \gamma=0.028 \times\left[\mathrm{M}_{\mathrm{t}}\right]^{0.84}\left[\mathrm{HNO}_{3}\right]^{1.29}
$$

\subsubsection{Calculation of the Cohesive Force under Acid Rain.} The cohesive forces of saturated montmorillonite-quartz sand remolded soils, which were reacted with $\mathrm{HNO}_{3}$ at $20^{\circ} \mathrm{C}$ for $0 \mathrm{~d}, 1 \mathrm{~d}(24.12 \mathrm{~h}), 5 \mathrm{~d}(113.50 \mathrm{~h}), 10 \mathrm{~d}$ (236.53 h), and $15 \mathrm{~d}$ $(357.70 \mathrm{~h})$, were calculated and compared with the measured values (without middle stage of acid immersion). The results are shown in Figure 5.

Figure 5 shows that the error between the theoretical calculated value and the measured value is small, and the theoretical calculated value changed from a rapid decline in the early stage to a slow decrease in the later stage and was consistent with the change of the measured value (except for the middle period of acid immersion). This change trend was also consistent with the convergence characteristics of the closed chemical reaction [20].

In the preparation process of remolded soil, despite repeated stirring, it was still difficult to achieve a theoretically uniform distribution of montmorillonite in the remolded soil, and it was inevitable that montmorillonite will be concentrated in the local position of soil sample. This increased the cement-montmorillonite contact area to a certain extent, making the measured value of cohesive force of montmorillonite-quartz sand remolded soil (22.31-26.18 $\mathrm{kPa}$ ) larger than the theoretical value of cohesion (21.74-23.15 kPa), but the overall error of the two was small, and the change trend was consistent. All of these showed that the calculation model of soil cohesive force under acid rain was successful.
TABLE 3: Reaction order and rate constant of montmorillonite$\mathrm{HNO}_{3}$.

\begin{tabular}{lccc}
\hline$T\left({ }^{\circ} \mathrm{C}\right)$ & $\alpha$ & $\beta$ & $k$ \\
\hline 20 & 0.84 & 1.29 & 0.02 \\
\hline
\end{tabular}

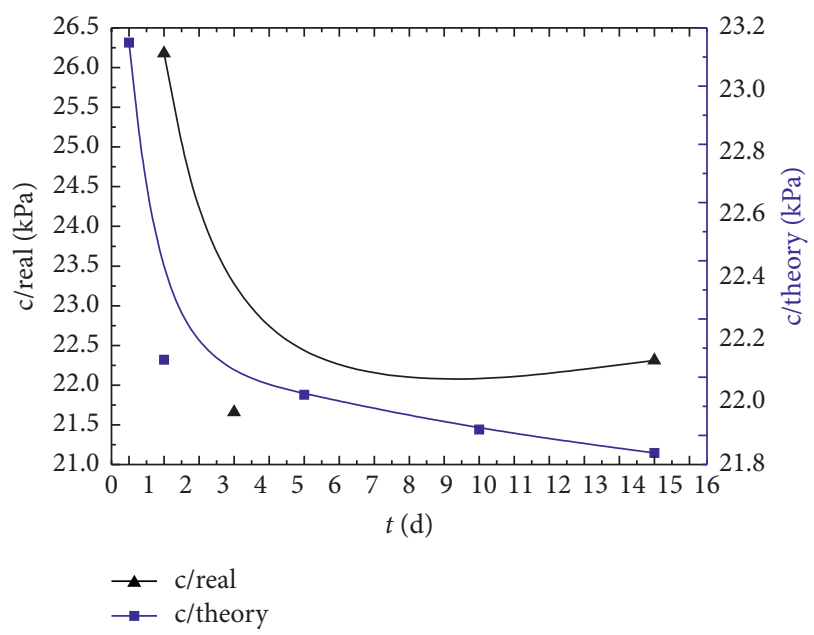

Figure 5: Comparison between theoretical and measured values of the cohesive force under acidic conditions.

\section{Conclusions}

(1) Montmorillonite reacted with the acid solution. $\mathrm{pH}$ of the immersion solution increased gradually, and the electrical conductivity (EC) generally showed a decrease. The cohesive force $c$ first decreased, subsequently increased, and then decreased again. The internal friction angle $\varphi$ basically remained unchanged. The change of the shear strength under acidic conditions was consistent with the change of cohesive force. Temperature greatly promoted the chemical reaction between $\mathrm{HNO}_{3}$ and montmorillonite.

(2) XRD comparison results before and after immersion indicated that the acid solution could dissolve montmorillonite, and no new substance was generated after the immersion, which mainly caused the decrease of soil cohesion.

(3) Combined with the change mechanism of cohesion, the cohesive force constitutive model of saturated montmorillonite-quartz sand remolded soil under acid rain was established. There was little error 
between the calculated value and the measured value, and the change trend of the theoretical calculated values was consistent with the one of the measured values, which indicates that the model established in this study was successful.

\section{Data Availability}

The data used to support the findings of the study are available from the corresponding author upon request.

\section{Conflicts of Interest}

The authors declare that they have no conflicts of interest.

\section{Acknowledgments}

This work was supported by the National Natural Science Foundation of China (Grant no. 41867040), Natural Science Foundation of Hebei Province, China (Grant no. E2020402075), and Innovation Fund Project of Hebei University of Engineering (Grant no. BSHJJ1904).

\section{References}

[1] J. Y. Gu, S. G. Cheng, and Y. H. Yang, "Experimental study on impact from acid rain on parameter of shear strength of landslide soil body," Water Resources and Hydropower Engineering, vol. 42, no. 10, pp. 36-39, 2011.

[2] I. Gratchev and I. Towhata, "Stress-strain characteristics of two natural soils subjected to long-term acidic contamination," Soils and Foundations, vol. 53, no. 3, pp. 469-476, 2013.

[3] G. Y. Xiao, X. J. Chen, and C. F. Wei, "Mechanism of permeability and control of compaction for red clay under the influence of acid rain," Chinese Journal of Rock Mechanics and Engineering, vol. 35, no. S1, pp. 3283-3290, 2016.

[4] Z. Bakhshipour, A. Asadi, B. B. K. Huat, A. Sridharan, and S. Kawasaki, "Effect of acid rain on geotechnical properties of residual soils," Soils and Foundations, vol. 56, no. 6, pp. 1008-1020, 2016.

[5] I. Gratchev and I. Towhata, "Compressibility of natural soils subjected to long-term acidic contamination," Environmental Earth Sciences, vol. 64, no. 1, pp. 193-200, 2011.

[6] I. Gratchev and I. Towhata, "Compressibility of soils containing kaolinite in acidic environments," KSCE Journal of Civil Engineering, vol. 20, no. 2, pp. 623-630, 2016.

[7] J. F. Zhang, Y. Huang, and B. X. Fan, "Yunnan laterite's shear character under the acid rain," Environmental Chemistry, vol. 36, no. 6, pp. 1353-1361, 2017.

[8] L. Xia and H. D. Gu, "Influence of acid rain on engineering properties of foamed light soil with river sludge," Journal of Civil, Architectural \& Environmental Engineering, vol. 40, no. 6, pp. 76-84, 2018.

[9] K. P. Li, X. Y. Zhao, D. Xiao et al., "Mechanism of acid rainchemical damage aggravating slaking behavior of silty mudstone," Rock and Soil Mechanics, vol. 41, no. 8, pp. 2693-2702, 2020.

[10] Z. L. Pan, Crystallography and Mineralogy, Geology Press, Beijing, China, 1993.

[11] C. X. Sun, J. H. Zhang J, L. C. Shu et al., "The Influence of acid rain and acid mist on clean Insulators' AC flashover performance," High Voltage Apparatus, vol. 26, no. 2, pp. 14-18, 1994.
[12] X. N. Gong, Advanced Soil Mechanics, Zhejiang University Press, Hangzhou, Zhejiang, China, 1996.

[13] Y. Zhao, P. Cui, and L. B. Hu, "Relation between evolution of clay shear strength and landslide induced by acid rain-taking landslides in three gorges reservoir area for example," Chinese Journal of Rock Mechanics and Engineering, vol. 28, no. 3, pp. 576-582, 2009.

[14] Y. Zhao, P. Cui, L. Hu, and T. Hueckel, "Multi-scale chemomechanical analysis of the slip surface of landslides in the Three Gorges, China," Science China Technological Sciences, vol. 54, no. 7, pp. 1757-1765, 2011.

[15] D. A. Laird, "Model for crystalline swelling of 2:1 phyllosilicates," Clays and Clay Minerals, vol. 44, no. 4, pp. 553-559, 1996.

[16] J. C. Jia, Q. Yang, and Q. Li, "Theoretical study on the swelling pressure of montmorillonites clay layers inundated with distilled water," Acta Mineralogica Sinica, vol. 30, no. 1, pp. 63-66, 2010.

[17] L. M. Barclay, A. H. Harrington, and R. H. Ottewill, "The measurement of forces between particles in disperse systems," Kolloid-Zeitschrift und Zeitschrift für Polymere, vol. 250, no. 7, pp. 655-666, 1972.

[18] J. B. Yuan, The Study for Properties of Bound Water on Clayey Soils and Their Quantitative Methods, South China University of Technology, Guangzhou, China, 2012.

[19] C. B. Cheng, Z. L. Kang, and Z. K. Xu, "Study on chemical kinetics of reaction between goethite and chlorhydric acid," Rock and Soil Mechanics, vol. 4, no. 3, pp. 41-46, 1993.

[20] Y. J. Yin, D. Z. Li, and Z. K. Xi, Brief Course of Physical Chemistry, Higher Education Press, Beijing, China, 2018.

[21] H. J. Qiu, M. M. Cao, Y. L. Wang et al., "Power law correlations of geohazards in loess hilly region," Scientia Geographica Sinica, vol. 35, no. 1, pp. 107-113, 2015.

[22] J. L. Yang, Soil Mechanics, China WaterPower Press, Beijing, China, 1992.

[23] K. A. Bagherzadeh and A. A. Mirghasemi, "Numerical and experimental direct shear tests for coarse-grained soils," Particuology, vol. 7, no. 1, pp. 83-91, 2009.

[24] X. Shi, J. Zhang, B. Liu et al., "Test of high-speed railway coarse grained filler of improved particle size distribution," Journal of Central South University (Science and Technology), vol. 45, no. 11, pp. 3964-3969, 2014.

[25] C. Chen, X. Liu, Z. D. Luo et al., "Study of strength and deformation characteristic of unbound granual material with different grain composition," Journal of Engineering Geology, vol. 24, no. 6, pp. 1191-1198, 2016.

[26] F. X. Jin, S. S. Qin, and Z. X. Yu, "Effect of coarse particles on shear strength of peddled silty clay," Soil Eng. and Foundation, vol. 33, no. 4, pp. 510-514, 2019.

[27] Y. Zhao, Study on Chemo-Mechanical Experiments of SlipSurface Formation, Graduate University of the Chinese Academy of Sciences, Beijing, China, 2005. 